\title{
POSLOVANJE INOVATIVNIH PREDUZEĆA U USLOVIMA DINAMIČNOG OKRUŽENJA
}

\section{INNOVATING COMPANIES DOING BUSINESS IN DYNAMIC AMBIENT}

\author{
Anja Stipankov, Fakultet tehničkih nauka, Novi Sad
}

\begin{abstract}
Oblast - INŽENJERSKI MENADŽMENT
Kratak sadržaj - Cilj ovog rada je da se utvrdi značaj $i$ uticaj inovacionog sistema države, startup ekosistema $i$ poslovnih inkubatora na razvoj poslovanja. Primenjena je metoda studije slučaja u kojoj su predstavljeni $i$ analizirani rezultati odabranih metoda za merenje inovativnosti države, analize za ocenjivanje tehnoloških uslova tržišta i komparativna analiza. Studija je izvršena posmatranjem dva poslovna inkubatora koji potiču iz Republike Srbije, odnosno Republike Italije.
\end{abstract}

Abstract - The aim of this paper is to determine the importance and impact of country's innovations system and city's start-up ecosystem on development of the business incubator through a case study in which innovation measuring tools, market condition analyses and benchmarking analysis have been applied. The study was conducted on two business incubators settled in Republic of Serbia, apropos Italian Republic.

Ključne reči: inovativnost, poslovni inkubator, startup ekosistem

\section{UVOD}

U doba modernizacije, kompanije su suočene sa konstantnim distrakcijama, potrebom za prilagođavanjem i umrežavanjem sa poslovnim svetom koji ih okružuje. Poslovni inkubatori, kao jedinstveni centri pomoći inovativnim preduzećima visokog potencijala rasta i razvoja, imaju kao glavni cilj smanjenje stepena neuspeha startup preduzeća i poboljšanje razvoja regiona u kojem funkcionišu. Postavlja se pitanje da li na dostignuti nivo uspešnosti poslovanja jednog poslovnog inkubatora utiče nacionalni nivo inovativnosti, odnosno stepen razvoja startup ekosistema posmatrane države. U

svrhu dobijanja odgovora na prethodne nedoumice, istraživački deo rada se deli na dva dela, dok su predmeti istraživanja, Poslovni Inkubator Novi Sad iz Republike Srbije i poslovni inkubator Polihub iz Republike Italije. Radi boljeg razumevanja, urađena je komparativna analiza eksternog okruženja odabranih država koja je elaborirana analizom inovativnosti i SWOT-PESTEL analizama tržišnih uslova.

U drugom delu istraživanja, urađena je analiza internog okruženja koje je definisano kao startup ekosistem na nivou grada u kojem se nalazi posmatrani inkubator.

\section{NAPOMENA:}

Ovaj rad proistekao je iz master rada čiji mentor je bio dr Vladimir Đaković, vanr. prof.
$\mathrm{Na}$ kraju istraživanja, predstavljena je komparativna analiza specifičnih karakteristika oba inkubatora, koja vodi do krajnjeg zaključka rada.

\section{PREDUZETNIŠTVO I INOVACIJE KAO KLJUČNI ELEMENTI RAZVOJA DRUŠTVA}

Savremeni svet je okarakterisan stalnim promenama društva. U takvim uslovima, osnova privrednog razvoja postaje preduzetništvo, ali i inovativni pristup privrednih subjekata tokom planiranja budućih poslovnih aktivnosti. Pored što podrazumeva neobilazan segment napretka i razvoja [1] preduzetništvo je proces u kojem se gotovo ni iz čega gradi nešto [2]. Dodatno, preduzetništvo je delatnost pojedinca usmerena na pokretanje, organizovanje i permanentno inoviranje organizacije, $s$ osnovnim ciljem stvaranja novog tržišta i ostvarivanjem dobiti. To je proces organizovanja, gde se, kroz inovaciju, vrši konverzija poslovne prilike $u$ tržišno prihvatljiv, dinamičan preduzetnički poduhvat [3].

Sa druge strane, inovacija predstavlja svaki sistem organizovanih i svrsishodnih aktivnosti koje su posledica kompleksnog i nestabilnog okruženja, a usmerenih na stvaranje novih vrednosti: proizvod, proizvodni proces, organizaciona struktura, stil upravljanja i slično. Unutar jedne države, preduzetništvo uz postojanje inovativnih aktivnosti, zajedno stvaranju nacionalni inovacioni sistem, to jeste startup ekosistem koji podrazumeva stub državnog prosperiteta. Startup ekosistem čine finansijski investitori, ljudi sa idejama, startup kompanije i njihove podržavajuće organizacije, odnosno institucije.

Među podržavajućim organizacijama, između ostalih, nalaze se i poslovni inkubatori koji jesu predmet istraživanja ovog rada i koji se definišu kao privredni subjekat sa ciljem da promoviše inovativnost i obezbeđuje svojim stanarima - startup kompanijama osnovne uslove privređivanja kako bi one mogle da usmere napore na poboljšanje stope uspešnosti poslovanja.

\section{KOMPARATIVNA ANALIZA INOVATIVNOSTI I TRŽIŠNIH USLOVA U REPUBLICI SRBIJI I REPUBLICI ITALIJI}

Iako postoje mnoge analize koje se bave istraživanjem poslovnog ambijenta, posebno će biti predstavljene analiza inovativnosti, SWOT analiza i PESTEL analiza. Cilj prvog dela istraživačkog rada jeste da utvrdi da li uspešnost poslovnog inkubatora zavisi od njegovog eksternog okruženja, odnosno dostignutog nivoa inovativnosti i/ili razvijenosti njegove matične države. U tu svrhu, ovaj deo rada analizira eksterno okruženje datih predmeta istraži- 
vanja. Sa jedne strane, analizira se Republika Srbija (njen indeks inovativnosti), kao eksterno poslovno okruženje Poslovnog Inkubatora Novi Sad. Sa druge strane se analizira Republika Italija (indeks inovativnosti i drugi odabrani elementi), kao eksterno poslovno okruženje Polihub start-up akceleratora u Milanu.

\subsection{Analiza Republike Srbije}

Prema analizi inovativnosti, na mapi Evrope koja izdvaja sve evropske inovacione sisteme prema njihovom stepenu postignutog faktora inovativnosti, Republika Srbija je označena žutom bojom čime je svrstana u grupu umerenih evropskih inovatora. Koristeći evropski alat za merenje inovativnosti pod nazivom European Innovation Scoreboard (skraćeno EIS) [4], kao predstavnici analize, izabrane su dve grupe indikatora: sveobuhvatni indeks inovativnosti (engl. Summary Innovation Index-SII) i indeks inovativnih aktivnosti (engl. Innovation activitiesIA) za posmatrani vremenski period od 2013. do 2018. godine. Posmatrajući prvu grupu indikatora, koja pokazuje nivo ulaganje države $u$ nacionalni inovacioni sistem u odnosu relativnom sa rezultatima Evropske Unije (skraćeno EU) u 2010 godini, saznaje se da je Republika Srbija, ulagala resurse za potrebe razvijanja inovacija uz minimalne oscilacije $\mathrm{i}$ minimalne razlike $\mathrm{u}$ odnosu vrednosti ulaganja.

U 2013. godini, Srbija postiže SII vrednosti 54.96, dok u narednoj godini beleži minimalni porast ulaganja. Nakon ove godine, vrednosti ulaganja počinju postepeno da beleže tendenciju rasta. Republika Srbija postiže maksimalnu vrednost ulaganja u svoj nacionalni inovacioni sistem prošle godine, u vrednosti 63.67.

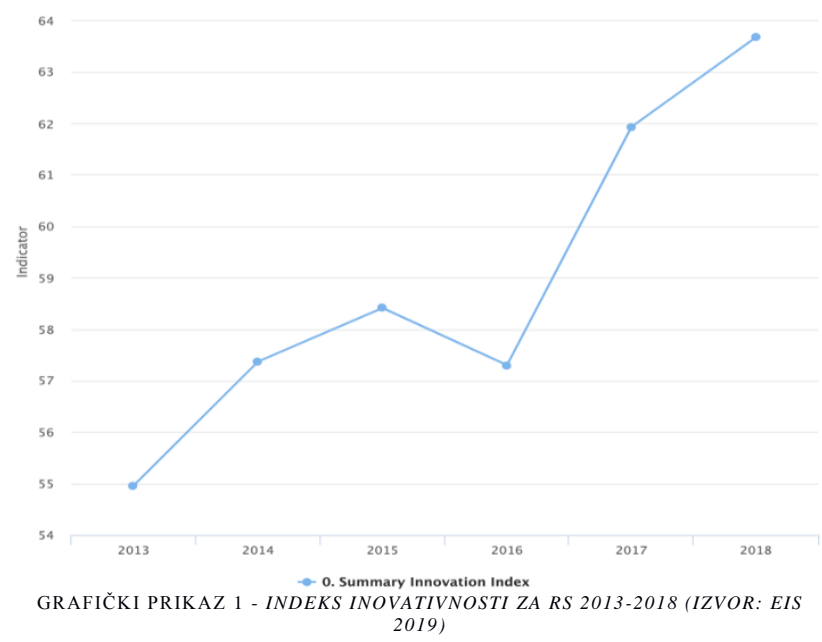

Kada se uzmu u obzir podaci dobijeni na osnovu druge grupe indikatora, koja predstavlja napore nastojanja u području inovacija na nivou preduzeća, saznaje se da je Republika Srbija najviše inovativnih kompanija imala u 2013. godini. Već naredne godine, indikator ulaganja kompanija u inovativne aktivnosti značajno opada i dostiže minimalnu vrednost od 73.76 2016. godine. Pomenuta vrednost ostaje nepromenjena sve do 2018. godine kada beleži rast na 87.44 .

Takođe, iako spada u grupu umerenih inovatora, prema podacima $E I S$-a iz 2017. godine, za sedam godina, Srbija postiže porast u svojim inovativnim aktivnostima od $17.3 \%$ u odnosu na performans EU u 2010. godini [5].

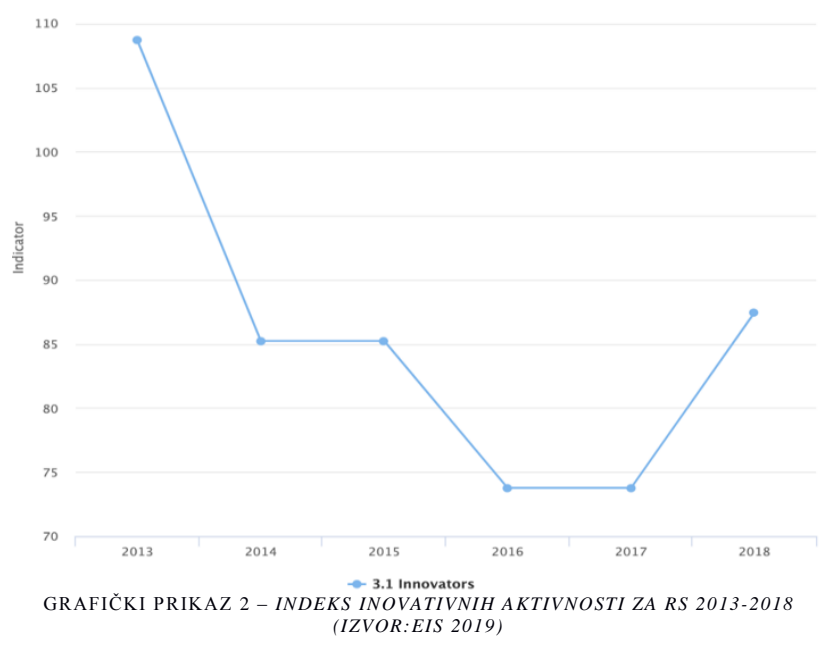

Prema SWOT analizi, najveća prednost za poslovanje inkubatora jeste geo-strateška pozicija Republike Srbije. Takođe, šansa Srbije jeste što predstavlja mlad startup ekosistem sa visoko-kvalifikovanim ljudstvom iz oblasti inženjerstva $\mathrm{i}$ informacionih tehnologija. Međutim, njene pretnje predstavljaju nestabilnost političke scene, visok nivo dispariteta $\mathrm{u}$ regionalnom razvoju i kontinuirana tendencija odlaska mladih i obrazovanih u strane zemlje u potrazi za finansijskom stabilnošću.

Na osnovu pregleda političkih faktora ove zemlje, saznaje se da Srbija nije članica EU i da održava nisko-umerenu političku stabilnost. Sa ekonomskog aspekta, bruto društveni proizvod Republike Srbije pokazuje kontinuirani rast u posmatranom vremenskom periodu i svrstava je $\mathrm{u}$ zemlje sa srednjom potrošačkom snagom. Socijalnodruštveni faktori pokazuju jednu kontradikciju u kojoj od 2013. godine zbog ekspanzivnosti trenda "odliva mozgova" se smanjuje broj stanovnika, dok kontinuirano raste broj zaposlenih.

U 2018.godini, Srbija postiže globalni indeks inovativnosti od $35.46 \%$ što je čini 55. na svetu. Takođe, prema tehničko-tehnološkim faktorima, u Srbiji raste broj stanovnika koji imaju pristup internetu. Sa ekološkog aspekta, sa postignutim ekološkim performansom od $57.49 \%$ zauzima 84 . mesto od 180 analiziranih zemalja, dok u pravnom smislu predstavlja državu koja pruža znatne olakšice startup kompanijama.

\subsection{Analiza Republike Italije}

Kao i Republika Srbija, Republika Italija je označena žutom bojom čime je svrstana u grupu umerenih evropskih inovatora. Grupa zemalja koje imaju inovacione sisteme umerenog karaktera označava zemlje koje imaju inovativni performans $50 \%$ do $90 \%$ od evropskog proseka. Posmatrajući grupe indikatora dobijenih na osnovu evropskog alata za merenje inovativnosti, prvo se sagledava indeks ukupne inovativnosti Republike Italije, to jeste SII.

Od 2013. do 2015. godine, nivo ulaganja u nacionalni inovacioni sistem Republike Italije ima tendenciju rasta i kreće se od 75.85 do 78.99, dok se 2016. godine spušta na vrednost indeksa 76.61. U vremenu posmatranja, maksimalni nivo ulaganja Italija dostiže u 2018. godini kada vrednost sveobuhvatnog indeksa inovativnosti dostiže 84.94 u odnosu na performans Evropske Unije u 2010. godini. 


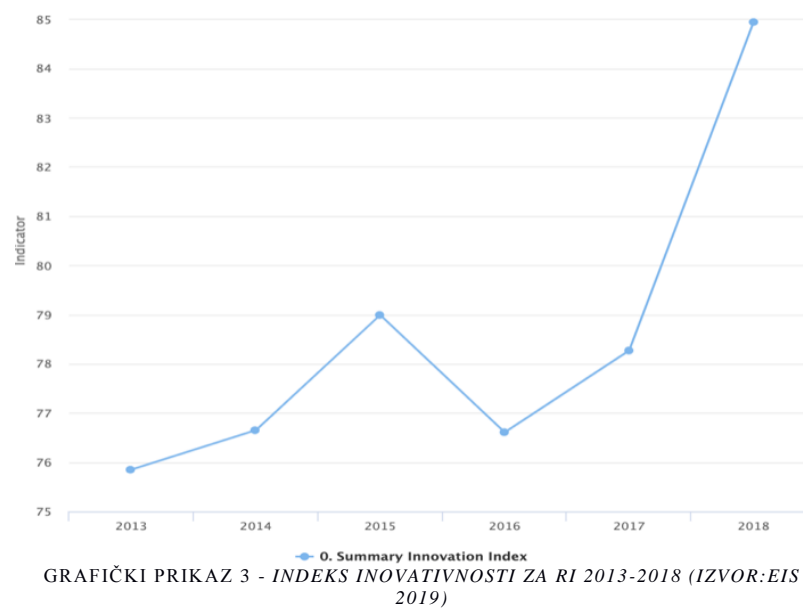

Podaci indikatora inovativnih aktivnosti, koji ističu inovativne napore sa aspekta kompanije, to jeste izvršenih od strane kompanija, pokazuju da Italiju karakterišu značajne oscilacije. Najveći napor u inovativne aktivnosti, prema vrednosti indikatora 119.59 , preduzeća ulažu tokom 2014. i 2015. godine. Već od 2016. godine inovativni napori kompanija opadaju na vrednost indeksa 91.32 koji ostaje nepromenjena do 2018. godine, kada raste na 118.52 što ipak ne prevazilazi maksimalnu vrednost prethodnih godina.

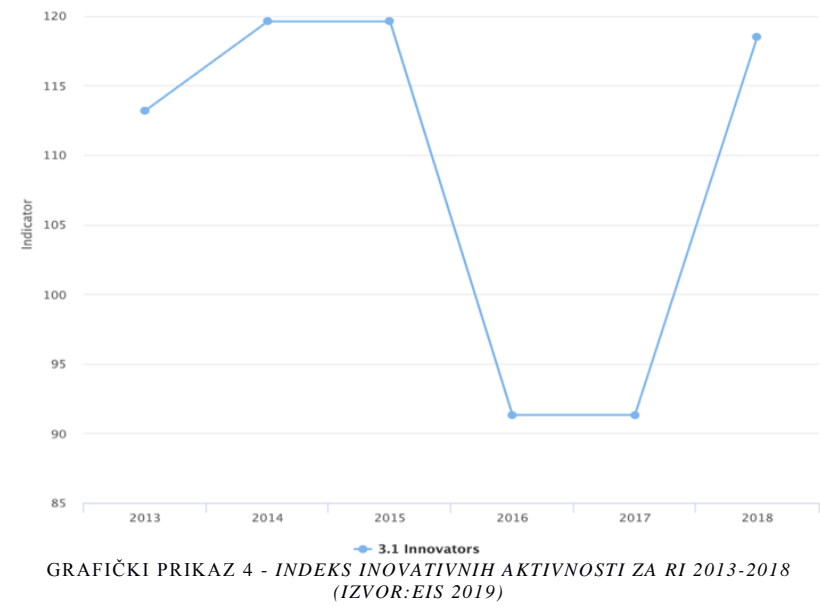

Na osnovu SWOT analize saznaje se da poslovanje u Republici Italiji nosi svoje prednosti, jer je Italija zemlja razvijenog prosperiteta i članica Evropske Unije. Italija predstavlja 3. najveću ekonomsku silu u Evrozoni. i napredovala po pitanju saradnje između akademije i industrije. Kao i Srbija, Italija ima veliki problem postojanja dispariteta $\mathrm{u}$ regionalnom razvoju $\mathrm{Uz}$ to, Italija nema trend kontinuiranog investiranja u sektor istraživanja i razvoja. Šansu predstavlja internacionalna saradnja sa drugim zemljama ili podsticaj od strane državnih institucija za veće ulaganje $u$ inovacioni sistem.

Prema PESTEL analizi, Italija teorijski predstavlja bolju osnovu za započinjanje biznisa, jer pripada Evrozoni koja podlaže istim zakonima i posluje prema zajedničkoj valuti. Takođe, ona je 12. država prema vrednosti bruto društvenog proizvoda.

Italija broji nešto više od 60 miliona stanovnika, sa padom od $0.8 \%$ u odnosu na 2017. godinu, dok stopa zaposlenosti raste od 2013. godine do danas. Prema globalnom indeksu inovativnosti, Italija je na 31. mestu u svetu, dok je prema indeksu ekološkog performansa na 16. mestu.

\section{KOMPARATIVNA ANALIZA KARAKTERISTIKA POSLOVNOG INKUBATORA NOVI SAD I POLIHUB-A}

U ovom radu, interno okruženje predmeta istraživanja jeste startup ekosistem Republike Srbije sa fokusom na Novi Sad, odnosno startup ekosistem Republike Italije sa fokusom na Milano. Pomenuti startup ekosistemi se istražuju, jer kako je objašnjeno u teorijskom delu rada, poslovni inkubatori jesu deo nacionalnih startup ekosistema, te su sa tim njihove karakteristike povezane uzročno-posledičnom vezom sa opštim stanjem koje preovladava u okviru državnih startup ekosistema. Cilj drugog dela istraživanja jeste da se utvrdi da li su interne karakteristike i stepen razvijenosti poslovnog inkubatora $u$ određenoj relaciji sa karakteristikama njegovog internog okruženja, odnosno nacionalnih startup ekosistema.

\subsection{Analiza Poslovnog Inkubatora Novi Sad}

Poslovni Inkubator Novi Sad (skraćeno BINS) se nalazi u Novom Sadu, u okviru startup ekosistema Srbije, koji se ove godine prvi put našao na listi američke organizacije Startup Genome. [6] Na ovaj način, Republika Srbija je postala jedini startup ekosistem posmatran u centralnoistočnoj Evropi. Vrednost domaćeg startup ekosistema se procenjuje na 300 miliona dolara, što nije značajno naspram svetskog proseka od 5 milijardi, ali za Srbiju predstavlja veliki dokaz napretka. Startup ekosistem u Srbiji kao prednost ima visoko-kvalifikovan kadar inženjera, što ga čini 5. u svetu. Dalje, Srbija ima znatne olakšice koje se odnose na (ne)plaćanje korporativne takse za startup kompanije tehnološkog tipa. Prema podacima Startupblink istraživačkog centra, Srbija je 36. na listi od 100 inovativnih zemalja. Novi Sad, kao jedan od startup ekosistema Republike Srbije zauzima 184. mesto od čak 1000 izlistanih startup gradova. [7] Poslovni Inkubator Novi Sad, osnovan je 2010 godine. BINS poseduje kapital u vrednosti od 250 do 300 hiljada dinara, u zavisnosti od godine posmatranja. Takođe, BINS uživa podršku domaćih državnih institucija, zatim visokoobrazovne institucije, ali i stranih organizacija koje imaju za cilj da unaprede njegov internacionalni razvoj. Iako ima u proseku dva zaposlena lica, BINS svojim stanarima pruža raznolik dijapazon usluga, u koje se ubraja: rešavanje svih administrativnih pitanja; usluge knjigovodstvenog i pravnog savetovanja; usluge konsaltinga i mentoringa u cilju razvoja i unapređivanja poslovnog modela startup stanara. Takođe, inkubator svojim korisnicima može da ponudi kadrovske usluge $u$ vidu pronalaženja novih zaposlenih i usluge umrežavanja, to jeste povezivanja sa akademskom istraživačima ili sa potencijalnim strateškim partnerima. Sa svojih 14 stanara, BINS zauzima drugo mesto $\mathrm{u}$ inovacionom sistemu Srbije, odmah iza beogradskog poslovnog inkubatora. Od 14 stanara, čak 36\% kompanija vrši delatnost računarskog programiranja. Na osnovu podele preduzeća prema veličini, to jeste broju zaposlenih, u BINS-u najviše su zastupljena mikro preduzeća, sa čak $72 \%$, dok su na drugom mestu srednja preduzeća. Na kraju, analizom karakteristika posmatranog inkubatora, saznaje se da je većina preduzeća osnovana 2017. godine. 


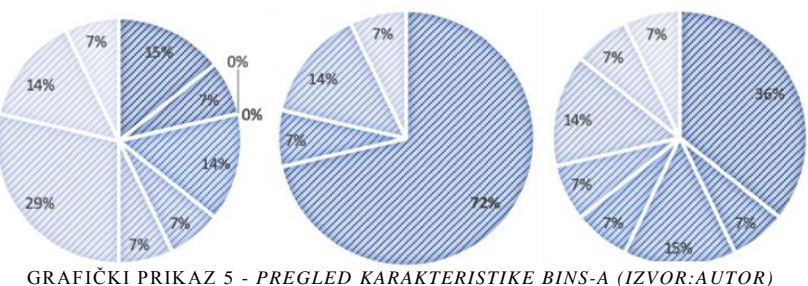

4.2. Analiza Polihub-a

Drugi predmet istraživanja rada jeste Polihub (skraćeno $\mathrm{PH}$ ), koji se nalazi u Milanu i pripada italijanskom startup ekosistemu. Interesantan podatak jeste da se startup ekosistem Republike Italije ne nalazi na istraživačkoj listi organizacije Startup Genome, što znači da nijedna institucija koja se bavi regulisanjem inovativnog sistema nije samoinicijativno podnela zahtev za uvrštavanje italijanskog startup ekosistema u svetsko istraživanje. Prema podacima Startupblink istraživačkog centra, Italija se nalazi na 25. mestu u svetu.

Milano, kao glavni inovacioni centar države je izgubio poziciju u top 50 gradova koju je imao 2017. godine i trenutno se nalazi na 57. poziciji. Poslednje, ali ne najmanje značajno jeste da se prema podacima italijanskog registra privrednih subjekata, u Milanu nalazi 1971. startup kompanija, koje zajedno predstavljaju ekosistem aproksimalne vrednosti od milijardu dolara. Polihub, koji predstavlja mesto okupljanja za 38 startup kompanija je drugo-rangirani akademsko-poslovni inkubator u Evropi i treće-rangirani u svetu. Osim podrške Politehničkog univerziteta u Milanu, Polihub uživa podršku i od drugih kompanija, državnih institucija, eksperata, investitora i preduzetnika, što omogućava da ostvaruje godišnji kapital između 100 i 250 hiljada evra. U proseku, ovaj poslovni inkubator ima od 11 do 50 zaposlenih što ga uvrstava u preduzeća srednje veličine. Polihub takođe pruža svojim stanarima različite usluge u okviru administracije, logistike, umrežavanja, konsaltinga, knjigovodstva, prava, marketinga, mentoringa, monitoringa, ali i pronalaženja adekvatnih investitora i obezbeđivanja izvora finansiranja. U Polihub-u, od 38 startup kompanija, najviše zastupljene su one koje se bave informaciono-komunikacionim tehnologijama, odnosno računarskim programiranjem se bavi $60 \%$ kompanija. Dodatno, prema broju zaposlenih najviše ima mikro preduzeća, koja zajedno čine 58\% preduzeća inkubatora. U Polihub-u, postoje kompanije koje su osnovane 2009. godine, ali i one osnovane 10 godina kasnije. Ipak, znatno više od ostalih ima kompanija koje su osnovane 2014. godine.
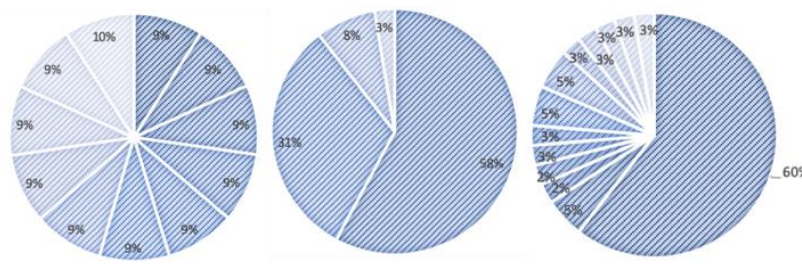

GRAFIČKI PRIKAZ 6 - PREGLED KARAKTERISTIKA POLIHUB-A (IZVOR: AUTOR)

\section{ZAKLJUČAK}

Posmatranje inovativnih rezultata nastalih merenjem inovativnog potencijala države, kao i njenih tržišnih uslova, predstavlja osnovu za definisanje strategije razvojne politike države. Republika Srbija je zemlja u razvoju i kao takva, ne dostiže Italiju za vrednosti obe grupe indikatora inovativnosti. Takođe, Italija je političko-ekonomski stabilnija država, sa bolje razvijenim tehno-ekološkim faktorima. Međutim, može se reći da je Srbija na dobrom putu i da je većinski broj indikatora pokazao da se njen napredak kreće uzlaznom putanjom. Drugo istraživanje pokazuje da iako je trenutno bolje rangirani, italijanski startup ekosistem stagnira, dok domaći ulaže znatno jače napore u njegovu modernizacije. Dakle, nezahvalno je zaključiti da trenutni presek stanja odražava obavezno identičnu sliku u narednim godinama. Posmatrajući predmete istraživanja, jasno je da milanski Polihub, iako je osnovan tri godine kasnije, prednjači nad novosadskim poslovnim inkubatorom u svim karakternim aspektima.

Međutim, postoje i određene sličnosti i slučajni trendovi, kao to da je najzastupljenija delatnost kompanija u oba slučaja računarsko programiranje, a broj zaposlenih u startup kompanijama biva pretežno mali, tako da su one mikro kompanije. $\mathrm{Na}$ osnovu prvog dela istraživanja zaključuju se da nivo dostignutog razvoja inovativnosti države utiče na uspešnost poslovnih inkubatora.

Takođe, moguće je zaključiti da razvoj startup ekosistema u kojem boravi poslovni inkubator utiče na njegovo poslovanje. Iako su rezultati skladni sa trenutnim stanjem u državama, još jednom vredi istaći da Srbija u nekoliko ključnih aspekata ima tendenciju rasta, dok Italija, iako generalno bolja, ne pokazuje znake jakog inovativnog pristupa.

\begin{tabular}{|c|c|c|}
\hline Karakteristike & BINS & PH \\
\hline Osnivanje & 2010 & 2013 \\
\hline Pravna forma & Mikro & Srednje \\
\hline Kapital & 250-300 hiljada dinara & 100-250 hiljada evra \\
\hline $\begin{array}{c}\text { Broj stanara } \\
\text { Obezbeđivanje svih } \\
\text { usluga }\end{array}$ & 14 & 38 \\
\hline Podrška institucija & $\mathrm{Ne}$ & Da \\
\hline TABELA 1 - PREGLED KARAKTERISTIKA BINS-A I PH-A (IZVOR: AUTOR) \\
\hline
\end{tabular}

\section{LITERATURA}

[1] J. Borocki, "Preduzetništvo, inovacije i razvoj preduzeća", Univerzitet u Novom Sadu, Fakultet tehničkih nauka, Novi Sad. 2014.

[2] J.A. Timmons, "New venture creation: Entrepreneurship for 21st Century", Babson College, 2009.

[3] N. Penezić, "Preduzetništvo-savremeni pristup", Akademska knjiga, 2009.

[4] European Innovation Scoreboard 2019, http://interactivetool.eu/EIS/EIS_2.html\#

[5] H. Hollanders, N. Es-Sadki, "European Innovation Scoreboard report", 2017.

[6] Startup Genome 2019, https://startupgenome.com/reports/global-startup-ecosystemreport-2019

[7] Startupblink 2019, https://www.startupblink.com/pdf/ecosystem_report.html

\section{Kratka biografija:}

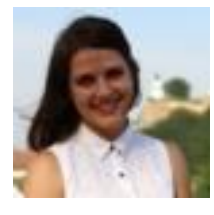

Anja Stipankov rođena je u Somboru, u Republici Srbiji, 1994. godine. Osnovne akademske studije završila je 2017. godine na Fakultetu tehničkih nauka iz oblasti Inženjerski menadžment. Master rad na Fakultetu tehničkih nauka iz oblasti Inženjerski menadžment odbranila je 2019. godine. 